International Journal of Child, Youth and Family Studies (2013) 2: 274-300

\title{
CANADIAN EARLY ADOLESCENTS' SELF-DISCLOSURE TO SIBLINGS AND BEST FRIENDS
}

\author{
Brynheld Martinez and Nina Howe
}

\begin{abstract}
This study addressed children's reports of self-disclosures to their siblings and best friends in early adolescence. Twenty-four boys and 22 girls in Grade 4 ( $M$ age $=9.48$, $S D=.59)$ and 19 boys and 28 girls in Grade $6(M$ age $=11.15$ years, $S D=.55)$ were interviewed regarding disclosures to siblings and friends. They also completed the Sibling Relationship Questionnaire (Furman \& Buhrmester, 1985b) and the Friendship Activity Questionnaire (Bukowski, Hoza, \& Boivin, 1994) to rate the quality of each relationship. Participants were more likely to disclose peer, academic, and shared interest issues to friends than siblings. Boys reported discussing shared interests more frequently with both siblings and friends. Respondents who disclosed to their sibling also reported higher warmth, rivalry, and greater conflict in their sibling relationship. Early adolescents who did not disclose to their friends reported greater friendship conflict. Findings are discussed in light of recent theory and empirical literature.
\end{abstract}

Keywords: self-disclosure, friendships, sibling relationships, relationship quality

Acknowledgement: This research was supported by a grant from the Social Sciences and Humanities Research Council of Canada to the second author as well as the Concordia University Research Chair in Early Childhood Development and Education. We would like to thank the children who participated and Marie-Hélène Brody, Lisa Fiorentino, Nadine Gariépy, Leigh Karavasilis, Alanna Lynch, Abby Ostien, and Stephanie Peccia for help with data collection and coding.

Please address correspondence to: Nina Howe, Department of Education, Concordia University, 1455 de Maisonneuve West, Montreal, Quebec, Canada H3G 1M8. Telephone: (514) 848-2424, extension 2008. E-mail: nina.howe@education.concordia.ca.

Brynheld Martinez is a doctoral student with an emphasis in School Psychology at the University of Rhode Island, 10 Chafee Road, Kingston, Rhode Island 02881 U.S.A.

E-mail: bmartinez@my.uri.edu

Nina Howe, Ph.D. is Professor of Early Childhood and Elementary Education and holds the Research Chair in Early Childhood Development and Education at Concordia University, Department of Education, 1455 de Maisonneuve Blvd. W., LB-579, Montreal, Quebec, Canada, H3G 1M8. E-mail: nina.howe@education.concordia.ca 
International Journal of Child, Youth and Family Studies (2013) 2: 274-300

Relationships theorists argue that close intimate relationships with both siblings and friends are important contexts for children's development (Carpendale \& Lewis, 2006; Dunn, 2002; Hartup, 1989; Hinde, 1979, 1995). These dyadic relationships may provide a context for the disclosure of intimate, personal information (Jourard, 1971), which is a defining feature of close relationships (Hinde, 1979). As children move into early adolescence, they develop greater abilities to engage in self-disclosure (Blockin, Crouter, Updegraff, \& McHale, 2011; Buhrmester \& Prager, 1995; Buhrmester \& Furman, 1990). Most research has focused on investigating selfdisclosure and links with relationship quality in either sibling relationships (e.g., Howe, AquanAssee, Bukowski, Lehoux, \& Rinaldi, 2001; Howe, Aquan-Assee, Bukowski, Rinaldi, \& Lehoux, 2000) or friendships (e.g., Altermatt \& Ivers, 2011; Buhrmester \& Prager, 1995; Rose \& Rudolph, 2006), but has rarely examined links between the two relationships. Although the two relationships are conceptually similar, they also differ in critical ways (e.g., voluntary nature, history of co-constructed experiences), which may influence children's propensity to engage in self-disclosure. Therefore, the present study examined (a) Grades 4 and 6 children's disclosure to their sibling and best friend, (b) disclosure across the two relationships, and (c) associations of disclosure and relationship quality.

\section{Sibling Relationships and Friendships as Contexts for Self-Disclosure}

Self-disclosure was originally defined by Jourard (1971) as the mutual revealing of personal information and feelings, and thus, is a central process in intimate relationships. The divulging of personal, intimate information informs two persons about one another and enhances closeness, while serving to maintain psychological well-being and increase one's self-awareness. Moreover, the pace, bi-directionality, and quality of disclosure between two individuals is related to the fondness and trust cultivated in their relationship and determines the course and depth of future disclosures. Jourard argued that individuals are likely to disclose their most private matters when relationships are high in intimacy and companionship. Hinde (1979) distinguished between breadth (i.e., extent of topics) and depth (i.e., how deeply the disclosure delved into personal issues) of disclosure, an important distinction for our purposes. Given that sibling relationships and friendships are crucial sources of closeness and intimacy, both provide contexts for disclosure (Dunn, 2002; Rubin, Bukowski, \& Parker, 2006).

Critical social and cognitive changes occur from middle childhood to early adolescence, which can influence children's social interactions, including the propensity for disclosure. As children devote greater attention to peers beginning in middle childhood, siblings and friends become the main sources and recipients of disclosure (Blockin et al., 2011; Buhrmester \& Prager, 1995; Furman \& Buhrmester, 1985b), although parents continue to be important recipients into and during adolescence (Smetana \& Metzger, 2008; Smetana, Metzger, Gettman, \& CampioneBarr, 2006; Stattin \& Kerr, 2000; Yau, Tasopoulos-Chan, \& Smetana, 2009).

Sibling self-disclosure. From infancy, siblings co-construct a long history of shared experiences and form intimate bonds; thus a child's earliest experience with self-disclosure may be with a brother or sister (Dunn, 1993; Howe et al., 2000). Sibling affiliations are characterized by both positive and negative affect, companionship, and individual perceptions of relationship quality (Howe, Ross, \& Recchia, 2011); further, siblings play a fundamental role in the 
International Journal of Child, Youth and Family Studies (2013) 2: 274-300

development of children's social skills and social understanding (Dunn, 2002; Howe et al., 2011), which may be important for the development of disclosure skills. Sibling self-disclosure is facilitated by reciprocal and mutual exchanges that encourage warmth, dependability, communication, and also hierarchical interactions that sometimes promote instrumental or emotional support (Howe et al., 2001; Howe et al., 2000).

In a seminal study, Buhrmester and Furman (1990) reported that compared to adolescents, younger children rated siblings as higher in companionship, intimacy, and affection. Although sibling companionship and intimacy decreased during adolescence (Updegraff, McHale, \& Crouter, 2002), levels of sibling disclosure remained consistent across middle childhood and early adolescence (Buhrmester \& Furman, 1987). Given that sibling interaction is an integral part of family dynamics (Kim, McHale, Crouter, \& Osgood, 2007; Yeh \& Lempers, 2004), family concerns were expected to be key topics of sibling disclosure (Howe, Aquan-Assee, \& Bukowski, 1995). Relative power between older and younger siblings may decrease as these relationships become more symmetrical over time (Buhrmester \& Furman, 1990), which may facilitate siblings' willingness to communicate and relate to each other's interests, difficulties, and experiences.

Disclosure between friends. Friendships are voluntary, more symmetrical than sibling relationships, and are commonly based on shared fondness, similar values, loyalty, and sensitivity (Berndt, 1982; Rubin et al., 2006). Young children rarely cite disclosure as an aspect of friendship, but beginning in early adolescence, disclosure is perceived as a defining feature of friendships (Altermatt \& Ivers, 2011; Dolgin \& Kim, 1994). Adolescents identify friends as individuals with whom they can share private feelings and concerns (Berndt \& Hanna, 1995; Dolgin \& Kim, 1994); as children mature, friendship intimacy ratings increase and adolescents report greater intimacy with friends than with siblings (e.g., Berndt \& Perry, 1986; Updegraff et al., 2002). Given expectations of commitment and trust, children may sometimes feel more comfortable confiding in friends than in siblings, particularly about peer relations. In fact, trust is conceptualized as a critical aspect of an individual's willingness to disclose to others (Smetana \& Metzger, 2008).

Disclosure across relationships. Although sibling relationships and friendships both offer intimacy and companionship for children during early adolescence (e.g., Kim et al., 2007; Updegraff \& Obeidallah, 1999), associations between the two relationships and links with development remain unclear (Updegraff et al., 2002). Nevertheless, interactions with siblings and friends offer a critical environment for facilitating children's social competence, because they share the features of companionship and affection and function as sources of emotional support and instrumental help (Dunn, 2002; Rubin et al., 2006). Despite their similarities, the two relationships vary in specific ways, which may influence the propensity and nature of disclosure. As Parker and Asher (1993) noted, the voluntary nature of friendships means that children must acquire important skills and understanding regarding how to maintain "commitment, personal responsibility, and loyalty" (p. 620), including the ability to establish a warm friendship partly based on intimate disclosures. Friendships may also be vulnerable to threats to the relationship (i.e., from conflict or lack of disclosure or gossip). In comparison, sibling relationships are not voluntary and will continue to exist whether or not children use these as a context to learn how to co-construct a warm and intimate relationship. Nevertheless, there is evidence that when siblings report warm and intimate relationships, they also have positive relationships with peers and 
International Journal of Child, Youth and Family Studies (2013) 2: 274-300

friends (e.g., Lockwood, Kitzmann, \& Cohen, 2001; van Aken \& Asendorpf, 1997) suggesting links across relationships (Howe et al., 2011). Given the limited research on sibling-friend linkages, one of our study's objectives - upon which we report here - was to investigate the associations of children's disclosures in these two key relationships.

Age and gender differences in disclosure. Girls perceive their relationships to be of greater significance and to provide more support for both siblings and friends compared to boys (Buhrmester \& Furman, 1987; Furman \& Buhrmester, 1985b). Further, females typically disclose at younger ages and higher rates than males (Berndt \& Hanna, 1995; Parker \& Asher, 1993; Rose et al., 2012; Rose \& Rudolph, 2006; Swenson \& Rose, 2009). Thus it appears that the gender constellation of sibling and friend dyads impacts intimacy and companionship, and therefore selfdisclosure (Buhrmester \& Prager, 1995; Dolgin \& Kim, 1994; Rose \& Rudolph, 2006). Further, same-sex siblings and friends report greater companionship and intimacy that is sustained into adolescence (Furman \& Buhrmester, 1985a, 1985b). While sisters are sometimes the recipients of disclosure (Buhrmester \& Prager, 1995), this is not always the case (Howe et al., 2001). Therefore we proceeded with the expectation that same-sex siblings and friends would be likely to confide in one another, with girls expected to engage in more disclosure than boys.

Disclosure and relationship quality. Friendship and sibling relationship quality is important in influencing ongoing interactions and children's social adjustment (Berndt, 2002; Buhrmester \& Furman, 1990; Dunn, 2002; Howe et al., 2011). Both same-sex and narrowlyspaced sibling dyads share high levels of closeness, while both opposite-sex sibling and widelyspaced dyads report less warmth and conflict (Furman \& Buhrmester, 1985b; Buhrmester \& Furman, 1990). Harmonious sibling relationships are high in warmth and low in conflict, while negative sibling relationships are perceived as high in conflict and low in warmth (Howe et al., 2011). It has previously been found that warm, intimate, and close relationships most likely offer optimal contexts for reciprocated sibling disclosure, emotional understanding (Howe et al., 2000; Howe et al., 2001), and strong social support (Kim et al., 2007). It has also been shown that children who do not trust their sibling reported that this was one reason for not engaging in disclosure; however, associations between trust and engaging in disclosure were not explored in this study (Howe et al., 2001). Nevertheless, as Buhrmester and Prager (1995) argue, not confiding may limit the opportunities for intimacy, warmth, and closeness in the relationship, whereas warmth appears to be critical in facilitating an optimal family climate for promoting disclosure. For example, adolescents' disclosure to parents about activities was associated with reciprocal features that define responsive and warm parent-child relationships including trust (Smetana \& Metzger, 2008). Interestingly, Greer and Campione-Barr (2011) reported that adolescents who disclosed to their siblings about activities and body-related issues had both a more intensely positive and negative relationship. Although sibling conflict may include intense negative exchanges, it does not threaten the continuation of the relationship due to the involuntary nature of sibling relationships, unlike intense friendship conflict that may lead to a breakdown of this voluntary relationship (Furman \& Buhrmester, 1985a). While highly antagonistic sibling relationships may not appear to foster reciprocal communication, Howe et al. (2000) did not find a significant negative association between rivalry or conflict and disclosure.

A number of studies have been conducted to examine the characteristics of high quality friendships and findings identify that greater positive and less negative affect (Berndt, 2002) and 
friendship stability over time (Bukowski et al., 1994) are associated with greater disclosure (Swenson \& Rose, 2009). In fact, Swenson and Rose (2009) reported that adolescents who rated their friendships as high in quality based on positive aspects of friendship (i.e., warmth) measured on the Network of Relationships Inventory or NRI (Furman, 1996), and who engaged in disclosure were also reliable reporters of their friends' internalizing symptoms. The internalizing symptoms were measured via items on a self-report questionnaire focused on problems (e.g., withdrawal), suggesting that warmth and intimate knowledge about the other were important factors (Swenson \& Rose, 2009). Additionally, these authors noted that perceiving a friendship as high quality could increase one's motivation to share and attend to a friend's feelings, behaviors, and thoughts. This idea highlights the bi-directional nature of close relationships.

Altermatt and Ivers (2011) also indicated that children who disclosed their success on an achievement-related task to a friend reported more positive affect when their friend had been supportive. They also found that children who rated their friendship as high in companionship on the Friendship Quality Questionnaire (Parker \& Asher, 1993) engaged in more help-seeking behavior toward each other. Further, in a study determining the important features of friendship, children's ratings of items regarding companionship (e.g., "My friend thinks of fun things for us to do together”) were strongly positively associated with items measuring security (i.e., reliance, trust), instrumental help, and closeness (Bukowski et al., 1994). Given this pattern of findings, one might expect that children who view friends as companions and feel valued by them might frequently engage in disclosure as argued by Smetana and Metzger (2008). Alternatively, as the friendship develops, each person may increase the degree of intimate self-disclosures in which they are likely to engage and thus perceive greater companionship and value in the relationship.

While the complexities of how, when, and to whom to self-disclose may be learned through communications with friends (Buhrmester, 1990), there is also the potential that those with limited social competence may be slower in developing these skills (Berndt \& Hanna, 1995). Also, the question of whether low quality friendships are characterized by less self-disclosure has not been addressed in the literature. However, we speculate that friendship defined by constant discord is probably a less suitable environment for self-disclosure, possibly due to the perceived lack of dependability or security provided by the peer. Perhaps friendships rated as low in quality may not be a context for disclosure because of a lack of trust, as has been found in the sibling relationship (Howe et al., 2001). Clearly, this is a question for further research.

In sum, based on the studies reviewed, when children perceive their relationships to be warm, intimate, and supportive, they are likely to engage in self-disclosure perhaps due to a high degree of trust between relationship partners. Of course, these are correlational studies, thus the direction of effect between relationship quality and self-disclosure is not known. Further, the question of how children perceive the quality of their sibling relationships and friendships and whether both are contexts for intimate self-disclosures has not been addressed. Nor is it known whether children who engage in self-disclosure in one relationship are likely to do so in the other, perhaps depending on the topic of disclosures. Overall, based on the literature, children's perceptions of their relationships are likely to influence the exchange of private information (and vice versa), but the defining conditions that encourage disclosure in these contexts are not entirely clear (Buhrmester \& Prager, 1995; Howe et al., 2000). 
International Journal of Child, Youth and Family Studies (2013) 2: 274-300

\section{The Present Study}

Our mixed-methods study examined the associations between children's self-disclosure to siblings and friends and links with both sibling and friendship relationship quality during the period of early adolescence. Our first objective was to identify the breadth (i.e., frequency and topics) of reported self-disclosure to siblings versus friends (Hinde, 1979). It was hypothesized that same-sex siblings and friends would engage more frequently in disclosure than opposite-sex dyads (Furman \& Buhrmester, 1985a, 1985b; Howe et al., 2001). To test this hypothesis comparing dyadic gender composition and disclosure, chi-square and McNemar's tests were employed. The second objective was to investigate gender and age differences in self-disclosure in the two relationships. It was hypothesized that girls would disclose more than boys (Rose \& Rudolph, 2006). Participants were predicted to disclose more to friends in Grade 6 than Grade 4 given the increasing importance of friends in children's lives (Swenson \& Rose, 2009). To assess the depth of disclosure, we investigated the degree to which children shared problems with their sibling or best friend (Hinde, 1979). Children were predicted to share peer problems with friends and family problems with siblings (Buhrmester \& Prager, 1995; Swenson \& Rose, 2009). Chisquare and McNemar's tests were also employed to test these hypotheses comparing gender and age differences in disclosure. The third objective was to examine the links between perceptions of relationship quality with sibling and friend disclosure. Based on Buhrmester and Prager (1995) and Howe et al. (2000), it was hypothesized that children who disclosed to their sibling would report greater sibling warmth and less conflict. We also predicted that disclosure to best friends would be positively associated with greater friend companionship and closeness, but less conflict. Finally, it was predicted that a positive sibling or friend relationship would be associated with increased disclosure in the two relationships (Howe et al., 2000; Swenson \& Rose, 2009). Univariate ANOVAs were conducted to ascertain the predicted associations between relationship quality and self-disclosure.

\section{Method}

\section{Design of Study}

A quasi mixed-methods design was employed in the present study, because a combination of methods was determined to be the most efficacious approach to addressing the hypotheses. First, in terms of data collection, children were individually interviewed using a qualitative method to allow them to answer the questions about disclosure in each child's own voice. Children also responded to two quantitative standardized questionnaires regarding sibling and friend relationship quality, because these measures are effective and efficient for assessing the different characteristics of relationships (e.g., warmth, conflict), as described in the procedure section. Second, in terms of coding of the data, the themes in the children's responses to the interviews were determined via a qualitative process, as described below. Also, quantitative scores for the subscales on the two relationship quality questionnaires were calculated. Third, as elaborated in the results section, the data were analyzed to determine if the hypotheses were supported or not. 
International Journal of Child, Youth and Family Studies (2013) 2: 274-300

\section{Participants}

A total of 93 target children in the 4th and 6th grades participated: Grade 4 (24 boys, 22 girls; $M$ age $=9.48$ years, $S D=.59)$; Grade $6(19$ boys, 28 girls; $M$ age $=11.15$ years, $S D=.55)$. Each participant was asked to identify his or her best friend through personal nomination with no limitations on age, grade, or school attended. Additionally, they identified the sibling to whom they felt closest. Recipient friend mean age was 9.41 years $(S D=.83)$ for 4 th graders and 11.53 years $(S D=.58)$ for 6th graders. Participants reported no cross-sex friendships and thus the gender composition of the recipient friends was identical to the sample. Of 4th graders, 24 identified a younger sibling as their recipient $(M$ age $=6.37, S D=1.86$; 10 male-male, 3 male-female, 6 female-male, 5 female-female dyads), while the remaining 22 chose an older sibling ( $M$ age $=$ 13.23 years, $S D=2.78$; 7 male-male, 4 male-female, 2 female-male, 9 female-female dyads). For 6th graders, recipient siblings included 23 younger siblings ( $M$ age $=8.0$ years, $S D=1.98$; 9 malemale, 1 male-female, 2 female-male, 11 female-female dyads), 22 older siblings ( $M$ age = 13.86 years, $S D=1.46$; 6 male-male, 4 male-female, 9 female-male, 4 female-female dyads) including two sets of twins ( $M$ age $=11.00$ years, $S D=.00$; 1 male-male, 1 female-female dyad). Lowerand middle-class English-speaking, mostly Caucasian children were recruited from local English elementary schools ${ }^{\mathrm{i}}$ in a large urban (population $=3,000,000$ ), bilingual (French-English) community in the majority French environment of Québec ${ }^{\text {ii }}$. Parental permission was obtained via a consent form and assent was obtained from children.

\section{Procedure}

Data were collected in the elementary school setting, either in the classroom or a separate room (e.g., library). As a group, children completed two questionnaires: (a) Sibling Relationship Questionnaire (Furman \& Buhrmester, 1985b), which measured perceptions of the quality of interactions with the recipient sibling; and (b) Friendship Activity Questionnaire (Bukowski et al., 1994), which measured perceptions of the quality of interactions with the best friend. These measures were selected because of their strong psychometric properties, appropriateness for measuring relationship quality, and also they are widely used in the literature. In addition, each child was individually and privately interviewed regarding the frequency, topics, and problems raised during sibling and friend self-disclosure; interviews were considered the appropriate method for determining this kind of qualitative information. These interviews were audiotaped, transcribed, and coded as described below.

\section{Measures}

Sibling Relationship Questionnaire (SRQ). The focal children completed the 48-item SRQ (Furman \& Buhrmester, 1985b) to evaluate the relationship quality with their closest sibling; this is a highly statistically reliable and efficient measure. Four dimensions were assessed: (a) warmth/closeness (e.g., "How much do you show your brother how to do things he doesn't know how to do?”); (b) relative power/status (e.g., "How much does your sibling tell you what to do?”); (c) conflict (e.g., "How much do you and your sister argue with each other?”); and (d) rivalry (e.g., "How much do you and your sister compete with each other?”). The response scale for each question included a 5-point Likert scale (from 1 = hardly at all to 5 = extremely much). 
International Journal of Child, Youth and Family Studies (2013) 2: 274-300

Cronbach's alphas assessed the internal consistency of the subscales in the present study: warmth (.93), conflict (.91), rivalry (.77), and power (.75).

Friendship Activity Questionnaire (FAQ). The focal children completed the 45-item FAQ (Bukowski et al., 1994) to assess friendship quality, which is a highly statistically reliable and efficient measure. Five dimensions were assessed: (a) companionship (e.g., "My friend and I spend a lot of our free time together."); (b) closeness (e.g., "I feel happy when I am with my friend.”); (c) help (e.g., "My friend and I help each other.”); (d) security (e.g., "I can trust and rely upon my friend.”); and (e) conflict (e.g., "I can get into fights with my friend.”). Children employed a 5-point Likert scale ranging from 1 (i.e., not true) to 5 (i.e., really true). In the present study, Cronbach's alphas measured the subscales' internal consistency: help (.89), closeness (.83), conflict (.74), security (.76), and companionship (.68).

Interview. The focal children were audiotaped during individual and private interviews (about 15 to 20 minutes) using a semi-structured format adapted from Howe et al. (2000) to include questions about friendships. Participants were asked 26 open-ended questions concerning the nature of disclosure to their sibling and best friend. First, each focal child was asked to identify the sibling to whom he or she felt closest and to name his or her best friend. Second, the child was asked if he or she disclosed to the sibling or best friend (i.e., "Do you share special thoughts with your sibling/best friend?”), the rate of disclosure (i.e., "How often do you share secrets?”), the topics shared (i.e., "What kind of things do you tell your sibling/best friend?”) and if they shared problems (i.e., "Do you ever share problems about your family?" "What kind of problems might you share?”).

After carefully reviewing the interview transcripts, a coding scheme was developed by categorizing recurrent themes in participants' responses (See Table 1). Operational definitions were developed for each of the five disclosure topics raised by participants: (a) family, (b) peer, (c) academic, (d) interest in the opposite sex, and (e) shared interests. Topics were coded dichotomously as either present or absent and all possible topics were coded. Responses to questions about problems regarding (a) family, (b) peer, and (c) academic issues were coded using the same dichotomous method. Finally, disclosure frequency to each recipient was coded on a 1to 4-item Likert scale: 1 = not often (i.e., once in a while); 2 = sometimes (i.e., once weekly); 3 = often (i.e., twice to four times weekly); 4 = very often (i.e., everyday).

\section{Reliability}

Two coders conducted interrater reliability on a random subsample of $20 \%$ (19/93) of the interviews; one coder was unfamiliar with the study's goals. Interrater reliability was calculated for topics disclosed to sibling and friend (kappa $=1.0, .97$, respectively), problems disclosed to sibling and friend (kappa $=1.0$ for both), frequency of disclosure to sibling and friend (kappa= 1.0, .93, respectively). Discrepancies were resolved through discussion.

\section{Results}

First, descriptive analyses were performed to identify the specific types of information and frequency of disclosure to siblings and friends. Second, we examined gender differences in 
International Journal of Child, Youth and Family Studies (2013) 2: 274-300

disclosure. Finally, descriptive statistics and associations of perceptions of sibling relationship and friendship quality were determined.

\section{Disclosure Recipients}

Descriptive information (raw frequencies, percentages) for disclosure topics and frequency of disclosure between friends and siblings are presented in Table 2; given the categorical binary nature of the interview data, we employed chi-square analyses and McNemar's tests. Most participants (63\%) reported disclosing to both their sibling and best friend, some disclosed only to their best friend (30\%), and a few disclosed only to their sibling (3\%) or to neither recipient (3\%). A 4 (categories of disclosure recipients) x 2 (disclosure, no disclosure) chi-square goodness of fit test revealed a statistically significant difference among these groups compared to expected values (see Table 2). Overall, participants were more likely to disclose only to their best friend or both recipients, and less likely to disclose only to their sibling or to neither recipient. These patterns were also evident in both grades; 4 (categories of disclosure recipients) x 2 (disclosure, no disclosure) chi-square goodness of fit test was significant for 4th grade, as well as 3 (categories of disclosure recipients) x 2 (disclosure, no disclosure) chi-square goodness of fit test for 6th grade participants. Given that there were no students who disclosed to neither a friend nor sibling, there are only three categories of disclosure recipients in this last analysis.

\section{Breadth and Depth of Disclosure to Siblings and Friends: Topics and Problems}

To assess breadth of disclosure, we examined the topics and problems (i.e., academic, peer, shared interests) revealed to recipients with McNemar's tests (see Table 3). Overall, approximately one-third of the sample reported discussing academic issues with their best friend (31\%) and sibling (32\%). Fourth graders were equally likely to report talking about academic issues to their best friend or their sibling (26\% to both), as were 6th graders (siblings = 38\%; friend $=36 \%$ ). McNemar's tests revealed no significant differences between children disclosing academic issues to a friend compared to a sibling. However, overall respondents were significantly more likely to discuss shared interests with friends (27\%) than siblings (12\%). Table 3 shows the same pattern in both grades, but 6th graders disclosed more about shared interests to a friend than a sibling.

Overall, 23\% of participants disclosed peer issues to their best friend (see Table 3), but significantly fewer (9\%) disclosed peer issues to their sibling. Overall, 20\% of participants disclosed their interest in the opposite sex significantly more to their best friend compared to their sibling (5\%); in particular, 6th graders were significantly more likely to confide interest in the opposite sex to their best friend (30\%) than their sibling (9\%). No significant differences were detected for revealing family issues with a friend or sibling, as frequencies were generally low.

To examine the depth of disclosure, we examined whether children revealed problems to their friend or sibling (see Table 3). Overall, best friends were significantly more likely than siblings to be recipients of problems regarding peers (80\% vs. 51\%) and academics (80\% vs. 52\%); 4th and 6th graders showed the same significant patterns for these two problem topics. Disclosing family problems to friends and siblings was not significant overall or within grades. 
International Journal of Child, Youth and Family Studies (2013) 2: 274-300

In summary, a majority of participants reported disclosing to both siblings and best friends. Respondents were more likely to discuss shared interests, peer issues and problems, interest in the opposite sex, and academic difficulties with their friends than their siblings, but no differences were apparent for family issues.

\section{Self-disclosure by Gender}

Gender differences. Next, we addressed gender differences in disclosure topics employing a series of 2 (disclosure, no disclosure of topic) x 2 (male, female) chi-square analyses (see Table 4). A significant difference was observed in the disclosure of shared interests for the total sample of 4th and 6th graders: Boys were more likely than girls to share details about hobbies and activities with both their best friend and sibling. When analyzing differences within grades, similar outcomes were obtained wherein 4 th grade boys significantly disclosed more about shared interests than girls to their best friends, while 6th grade boys were more likely than girls to disclose about shared interests to both their best friends and siblings. In terms of disclosing problems, overall girls were significantly more likely to disclose family and peer problems, but only to their sibling. Sixth grade girls were more likely to talk about family problems than boys to their best friends. Fourth grade girls revealed more peer problems to their friends than boys, as well as more family problems to siblings. Regarding disclosure frequency, a one-way ANOVA, $F(1,40)=7.90, p<.01$, indicated that 4 th grade girls $(M=2.71, S D=1.23)$ disclosed significantly more often to their best friends than boys $(M=1.81, S D=.81)$, which supported the hypothesis that girls may disclose more than boys, particularly to their best friend.

Same-gender versus opposite-gender sibling dyad differences. To address the question of sibling dyadic gender differences in disclosure, a series of 3 (brother-brother, sister-sister, brothersister) x 2 (disclosure, no disclosure) chi-square analyses were performed (see Table 5). Support was evident for the hypothesis that same-sex sibling dyads would disclose more to one another than opposite-sex pairs; however, there was no significant difference between sister-sister and brother-brother dyads. Sister-sister dyads and opposite-sex dyads reported disclosing significantly more family problems than brother-brother dyads, thus providing support for the hypothesis that dyads with one female have a greater likelihood of engaging in disclosure.

Same-gender sibling versus friendship dyad differences. Due to the lack of oppositegender friendships within the sample, comparisons between same- and opposite-gender friendships were not possible. However, in the analysis of differences between same-sex sibling and friend dyads, we employed a 2 (disclosure, no disclosure) x 2 (boy-boy, girl-girl) chi-square analysis (see Table 5). Brother-brother dyads significantly disclosed more about academic issues than boy-boy friend dyads. On the other hand, male friend dyads were significantly more likely to disclose academic problems compared to brother-brother dyads. A significant difference was found in girls' disclosure of shared interests, wherein girl-girl friends were more likely than sistersister dyads to discuss hobbies and activities.

\section{Self-disclosure and Perceptions of Relationship Quality with Siblings and Friends}

Self-disclosure and sibling relationship quality. Descriptive statistics for the subscales on the sibling and friendship measures of relationship quality are reported in Table 6. ANOVAs were 
International Journal of Child, Youth and Family Studies (2013) 2: 274-300

conducted to examine differences in sibling relationship quality by disclosure (see Table 7). These analyses employed the constructs of relationship quality (i.e., warmth, rivalry, conflict) as separate dependent variables, with the presence or absence of disclosure as the independent variable. Consistent with the hypothesis that sibling relationship quality variables would differ between groups who engaged (or not) in sibling disclosure, significant differences were revealed for warmth, rivalry, and conflict (See Table 7). Participants who disclosed to their sibling scored significantly higher on warmth than those who did not disclose, thus, supporting the hypothesis. For rivalry, children who engaged in sibling disclosure scored significantly higher on rivalry than those who did not disclose. Finally, for conflict, individuals who disclosed to a sibling reported more conflict compared to those who did not disclose, which did not support the hypothesis.

Self-disclosure and friendship quality. A one-way ANOVA was conducted on each of the five subscales of friendship quality and a significant difference between groups was found only for conflict, $F(1,45)=4.25, p<.05$; specifically, there were lower levels of conflict for 6th graders who disclosed to their best friend $(M=2.40, S D=.84)$ compared to those who did not $(M=3.70$, $S D=1.84)$. This finding provided partial support for the hypothesis that best friends who disclosed to one another would be less likely to report conflict.

\section{Discussion}

First, we discuss the nature of children's disclosures to siblings and best friends. Second, we analyze gender and age effects. Lastly, associations with relationship quality are considered.

\section{Children's Disclosures to their Sibling and Best Friend}

Most boys and girls reported engaging in self-disclosure with both siblings and friends during the transition into early adolescence; very few participants reported a preference for disclosing only to their sibling or neither recipient. However, if children preferred one recipient, it was most likely to be their best friend. Although disclosure is a defining characteristic of friendships, it may not necessarily be as strongly evident between siblings, which may account for the pattern of findings (Hartup \& Stevens, 1997). It is likely that sibling disclosure may be influenced by age differences, personalities, and relationship quality (Howe et al., 2000; Howe et al., 2001), and thus a more detailed analysis is warranted.

The findings suggest that friend and sibling relationships fulfill different functions as disclosure recipients. For example, while individuals were equally likely to disclose academic issues to both recipients, shared interests were discussed more with friends than siblings. This is consistent with theory and previous research indicating that during this developmental period children form connections based on "concrete reciprocities” (Hartup \& Stevens, 1997, p. 356), such as common activities and hobbies, and seek out others who are similar in various ways (Hinde, 1979). Apparently, shared interests may be more significant for older than younger children, perhaps because friends may be their main companions. Since friends are important resources (Hartup \& Stevens, 1997), it was not surprising early adolescents confided peer concerns to best friends rather than to siblings. Due to the importance of peer relations in early adolescence (Bukowski et al., 1994; Rubin et al., 2006), best friends may be perceived to be more knowledgeable, sympathetic, and relate more easily to these issues than siblings (Buhrmester \& 
International Journal of Child, Youth and Family Studies (2013) 2: 274-300

Prager, 1995). Certainly, romantic interests were divulged at higher rates to best friends, perhaps because friends know the person of interest, understand emotions regarding the opposite sex, and are more trustworthy with this delicate information compared to siblings. Trust has been identified as a key ingredient in an individual's willingness to disclose (Smetana \& Metzger, 2008). Howe et al. (2001) reported one reason early adolescents did not disclose to siblings was a lack of trust, for fear of being teased, criticized, or having information communicated to parents.

Although participants did not differentially disclose to siblings and friends about general school issues, they did prefer to share academic problems and difficulties with their friends, perhaps because they were in the same class or grade. Instrumental help is a principal attribute of friendships (Bukowski et al., 1994); thus, if one's best friend is knowledgeable in a specific subject, the focal child may choose to ask the best friend for help or confide difficulties rather than a sibling, especially if the sibling is younger.

Similar to general peer issues, peer problems were most likely to be disclosed to best friends. Friends are familiar with one another's peer groups, social status, and disliked peers, and thus they may be a better source of advice and protection from peer victimization than siblings (Bukowski et al., 1994). Unexpectedly, family incidents and crises were disclosed equally to both siblings and friends in both grades, although gender was an important factor as noted below. The low rates of disclosure about family issues suggested that either they were of less concern or perhaps parents were more likely recipients (Stattin \& Kerr, 2000; Yau et al., 2009).

\section{Gender and Age Differences}

Clearly, boys and girls disclosed different topics and problems with their best friends compared to their siblings. Males generally disclosed shared interests to both recipients, suggesting their relationships were activity oriented. While mutual activities are a fundamental aspect of friendships (Berndt, 2002; Hartup, 1989; Hartup \& Stevens, 1997), our findings draw attention to its value in sibling relationships, specifically for boys. Further, boys' hobbies may be of greater importance than personal issues or problems (Rose et al., 2012), which in is line with work suggesting that boys may be less interested in interpersonal problems.

Interestingly, brothers reported discussing general academic topics more compared to boyboy friend dyads. However, male friend dyads were more likely to share serious academic problems than brothers. These findings may indicate that while boys talk to their siblings about broad school issues, they may be sharing major academic concerns primarily with their friends, possibly because friends may simply be disclosing more intimate or sensitive information (Berndt \& Hanna, 1995; Berndt \& Perry, 1986; Dolgin \& Kim, 1994), particularly about academics. It is also possible that boys may perceive their same-sex friends as better sources of emotional and instrumental support (Hartup \& Stevens, 1997) compared to their brothers.

Alternatively, females were more inclined to talk about family and peer problems, but exclusively with their siblings, perhaps due to greater emotional support and intimacy females perceive in sibling relationships compared to males (Buhrmester \& Furman, 1987). In addition, girls divulge private emotions and information at a younger age than boys (Buhrmester \& Prager, 1995; Rose et al., 2012), suggesting competence in using self-disclosure as a means of self- 
International Journal of Child, Youth and Family Studies (2013) 2: 274-300

expression and for obtaining social input regarding their personal experiences and dilemmas. Siblings often engage in disclosure early in their relationships (Howe et al., 1995), and as a result of their shared history may have developed closeness and trust, which may account for greater discussion of troubles regarding family and peers. However, girlfriends are more likely to discuss shared interests compared to sisters, which is consistent with the premise that friendships are based on mutual hobbies and shared activities (Berndt, 2002; Hartup, 1989; Hartup \& Stevens, 1997).

Early adolescence is a period when individuals begin to spend less time with their family (Updegraff \& Obeidallah, 1999), interact more with their peer groups (Berndt, 1982), and experience increased sibling conflict (Lempers \& Clark-Lempers, 1992). At the same time, early adolescents may share more about peer problems with their best friends due to the increasing focus on peers and social status (Berndt, 1982; Dolgin \& Kim, 1994; Lempers \& Clark-Lempers, 1992). As boys and girls individuate themselves from their family, they may feel that the family does not provide the emotional support or advice needed to navigate their peer groups and the developmental challenges of adolescence. Also, reports of confiding about interest in the opposite sex increased in early adolescence (Dolgin \& Kim, 1994), which is consistent with the reports that early adolescents share more about attraction, romance, and cross-gender relationships than younger children (Buhrmester \& Prager, 1995; Dolgin \& Kim, 1994).

When investigating within grades, both Grade 4 and Grade 6 males reported disclosing more than females about shared interests with their best friends, which again supports the high priority that activities have in males' friendships across this developmental period. However, older males also disclosed about shared interests to their sibling. This pattern may also indicate that the greater symmetrical power and increasing reciprocal exchanges evident between siblings as they mature (Buhrmester \& Furman, 1990) may increase the likelihood of engaging in common activities. Grade 6 girls reported disclosing more family problems to both recipients compared to males and younger girls. Perhaps in early adolescence, females are more comfortable and capable of sharing concerns (Rose et al., 2012) with their best friends and siblings compared to boys and younger children.

Surprisingly, although 4th grade girls disclosed more overall to their best friend than boys, 6th graders did not prefer their best friend as a disclosure recipient, as prior research suggested (Buhrmester \& Furman, 1987; Updegraff et al., 2002). Disclosure processes and intimacy in the friendships of the 6th graders may still be developing as they enter the period of early adolescence, perhaps accounting for the rather weak age differences. Variations in the relationship history of friends or siblings may also be critical and require further examination.

In conclusion, the gender findings are in line with prior research revealing that girls disclose more to girls (Buhrmester \& Prager, 1995; Dolgin \& Kim, 1994; Rose \& Rudolph, 2006), and that youngsters disclose more information to same-sex than opposite-sex siblings (Howe et al., 1995). Yet, girl-girl dyads did not report disclosing more than boy-boy dyads, suggesting that merely having a same-sex sibling may facilitate greater self-disclosure. 
International Journal of Child, Youth and Family Studies (2013) 2: 274-300

\section{Associations of Disclosure and Relationship Quality}

Sibling disclosure was positively correlated with the sibling relationship quality constructs of warmth, rivalry, and conflict, indicating its important association with relationship quality. These findings were partly in line with Howe et al. (2000), who reported that self-disclosure was likely to occur along with positive emotions, which may encourage communication between siblings. Sibling disclosure most likely is associated with intimacy and trust (Howe et al., 2000; Howe et al., 2001; Smetana \& Metzger, 2008), which may also reflect warmth between siblings. Alternatively, siblings may have developed supportive and receptive communicative exchanges as a consequence of early and regular positive interaction or contact (Howe et al., 2000).

Contrary to the hypothesis, sibling conflict and rivalry were not lower when children reported engaging in disclosure, which is in line with reports that adolescents' disclosures about activities were associated with both positive and negative sibling interactions (Greer \& CampioneBarr, 2011). Perhaps, siblings who disclose to one another may interact more frequently than those who do not disclose, thus increasing opportunities for disputes perhaps due to the intimate quality of their relationship. Howe et al. (2000) also proposed that siblings who shared negative experiences and affect may increase the likelihood of disclosure, perhaps because they have advanced social skills and social understanding that allows them to resolve their issues through disclosure. For example, constructive (e.g., collaborative resolution, reasoning) rather than destructive (e.g., hostile, aggressive behaviors) conflict resolution strategies may characterize siblings who disclose to one another (Howe et al., 2011), but this warrants further study. While rivalry's association with disclosure has not been investigated previously, our findings indicate that it is a factor to be considered. Rivalry has been associated with a negative sibling relationship, but only if a child perceived parental differential treatment as excessive (Howe et al., 2011). Perhaps, if children believe their perceptions of parental differential treatment are fair, disclosing may help them to understand parents' and siblings' motivations for their behavior, a speculation meriting further investigation.

Unexpectedly, only one feature of friendship quality (i.e., conflict) was perceived to vary along with friend disclosure, but only for older boys and girls. Given that friendships are often based on mutual liking (Hartup \& Stevens, 1997), children may select friends who place a similar value on disclosure. Nevertheless, as expected, early adolescents who did not disclose to their friends reported greater friendship conflict. This pattern may be associated with friends drawing apart and eventually to a breakdown of the relationship (Hartup, 1989). Discord and tension between friends may intensify if they do not discuss and resolve their problems, while friendships already high in conflict may simply be running their course towards dissolution.

The disclosure competencies learned and/or applied in the sibling relationship may have continuing effects, as they were associated with more disclosure between friends in both grades. Perhaps children who have siblings, may have previously developed and used social and communication skills in the family context that can be easily transferred, extended, and enhanced with close friends. Alternatively, children and adolescents who engage in disclosure with their friends and experience beneficial effects may also promote it in their sibling relationships. In conclusion, the processes of disclosure appear to play an important and meaningful role in enriching both sibling relationships and friendships, in line with theory (Buhrmester \& Prager, 
International Journal of Child, Youth and Family Studies (2013) 2: 274-300

1995; Carpendale \& Lewis, 2006). Ultimately, the more satisfied children were with their relationships, the more frequent disclosure behavior was displayed. Although perceptions of quality can differ between relationship partners (Hartup \& Stevens, 1997), mutual positive interactions likely contribute to the reciprocated exchange of confidential information.

\section{Conclusion}

Due to the fairly homogenous population, the findings may not apply to children of other ethnic and social backgrounds, which should be addressed in future work. The relatively small sample size reduces the feasibility of using complex analytical approaches; however, the interviews provide a rich source of data that cannot easily be obtained from questionnaires. Individual attributes such as temperament, extroversion, and liking the recipient have been associated with disclosure (Buhrmester \& Prager, 1995; Jourard, 1971), but were not investigated in the present study. Given the dyadic nature of relationships and the interdependence of the data, future studies should take into account the experience of each child in each relationship. Nevertheless, an individual's perceptions are important influences on interactions and relationship quality (Hinde, 1979, 1995) and thus, the frequency of self-disclosure. The history of a friendship may also be a potential factor with longer friendships being associated with more trust and intimacy, thus warranting future investigation. Lastly, individuals’ perceptions of the roles and functions of sibling relationships and friendships in their lives should be examined.

The present study is one of the first to compare boys' and girls' disclosure in friendships and sibling relationships in the transition to early adolescence. This investigation not only extends the literature, but also illuminates some of the links between these two critical relationships for young adolescents, particularly in terms of dyadic structure, relationship quality, and disclosure processes. Healthy relationships with siblings and friends, characterized by closeness, care, and mutual support, are important for children's enhanced social-emotional development and adjustment, as well as overall well-being. Self-disclosure may facilitate the development of highquality dyadic relationships. Our findings should inform parents, teachers, and clinicians by highlighting the need for educational programs, interventions, and strategies that help children and adolescents develop and sustain satisfying relationships through self-disclosure. 
International Journal of Child, Youth and Family Studies (2013) 2: 274-300

\section{References}

Altermatt, E. R., \& Ivers, I. E. (2011). Friends’ responses to children's disclosure of an achievement-related success: An observational study. Merrill-Palmer Quarterly, 57(4), 429-454.

Berndt, T. J. (1982). The features and effects of friendship in early adolescence. Child Development, 53(6), 1447-1460.

Berndt, T. J. (2002). Friendship quality and social development. Current Directions in Psychological Science, 11, 7-10.

Berndt, T. J., \& Hanna, N. A. (1995). Intimacy and self-disclosure in friendships. In K. J. Rotenburg (Ed.), Disclosure processes in children and adolescents (pp. 57-77). Cambridge, UK: Cambridge University Press.

Berndt, T. J., \& Perry, T. B. (1986). Children’s perceptions of friendships as supportive relationships. Developmental Psychology, 22(5), 640-680.

Blockin, M. K., Crouter, A. C., Updegraff, K. A., \& McHale, S. (2011). Sources of parental knowledge in Mexican American families. Family Relations, 60(1), 30-44.

Buhrmester, D. (1990). Intimacy of friendship, interpersonal competence, and adjustment during preadolescence and adolescence. Child Development, 61(4), 1101-1111.

Buhrmester, D., \& Furman, W. (1987). Development of companionship and intimacy. Child Development, 58(4), 1101-1113.

Buhrmester, D., \& Furman, W. (1990). Perceptions of sibling relationships during middle childhood and adolescence. Child Development, 61(5), 1387-1398.

Buhrmester, D., \& Prager, K. (1995). Patterns and functions of self-disclosure during childhood and adolescence. In K. J. Rotenberg (Ed.), Disclosure processes in children and adolescents (pp. 10-56). New York: Cambridge University Press.

Bukowski, W. M., Hoza, B., \& Boivin, M. (1994). Measuring friendship quality during pre- and early adolescence: The development and psychometric properties of the Friendship Qualities Scale. Journal of Social and Personal Relationships, 11(3), 471-484.

Carpendale, J. I. M., \& Lewis, C. (2006). How children develop social understanding. Oxford, UK: Blackwell.

Dolgin, K. G., \& Kim, S. (1994). Adolescents’ disclosure to best and good friends: The effects of gender and topic intimacy. Social Development, 3, 146-157. 
International Journal of Child, Youth and Family Studies (2013) 2: 274-300

Dunn, J. (1993). Young children's close relationships: Beyond attachment. Newbury Park, CA: Sage Publications.

Dunn, J. (2002). Sibling relationships. In P. K. Smith \& C. H. Hart (Eds.), Blackwell handbook of childhood social development (pp. 223-237). Oxford, UK: Blackwell.

Furman, W. (1996). The measurement of children and adolescent's perceptions of friendships: Conceptual and methodological issues. In W. M. Bukowski, A. F. Newcomb, \& W. W. Hartup (Eds.), The company they keep: Friendships in childhood and adolescence (pp. 4165). Cambridge, MA: Cambridge University Press.

Furman, W., \& Buhrmester, D. (1985a). Children's perceptions of the personal relationships in their social networks. Child Development, 56(2), 448-461.

Furman, W., \& Buhrmester, D. (1985b). Children’s perceptions of the qualities of sibling relationships. Developmental Psychology, 21(6), 1016-1024.

Greer, K. B., \& Campione-Barr, N. (2011, April). I say you say: Sibling disclosure and associations with relationship quality and adjustment. Poster presented at the biennial meeting of the Society for Research in Child Development, Montreal, Canada.

Hartup, W. W. (1989). Social relationships and their developmental significance. American Psychologist, 44(2), 120-126.

Hartup, W. W., \& Stevens, N. (1997). Friendships and adaptation in the life course. Psychological Bulletin, 121(3), 355-370.

Hinde, R. A. (1979). Towards understanding relationships. London, UK: Academic Press.

Hinde, R. A. (1995). A suggested structure for a science of relationships. Personal Relationships, 2, 1-15.

Howe, N., Aquan-Assee, J., \& Bukowski, W. M. (1995). Self-disclosure and the sibling relationship: What did Romulus tell Remus? In K. J. Rotenberg (Ed.), Disclosure processes in children and adolescents (pp. 78-99). New York: Cambridge University Press.

Howe, N., Aquan-Assee, J., Bukowski, W. M., Lehoux, P., \& Rinaldi, C. (2001). Siblings as confidants: Emotional understanding, relationships warmth, and sibling self-disclosure. Social Development, 10(4), 440-454.

Howe, N., Aquan-Assee, J., Bukowski, W. M., Rinaldi, C., \& Lehoux, P. (2000). Sibling selfdisclosure in early adolescence. Merrill-Palmer Quarterly, 46(4), 653-671. 
International Journal of Child, Youth and Family Studies (2013) 2: 274-300

Howe, N., Ross, H. S., \& Recchia, H. (2011). Sibling relations in early childhood. In C. Hart \& P. K. Smith (Eds.). Wiley-Blackwell handbook of childhood social development (2nd ed., pp. 356-372). New York: Wiley.

Jourard, S. M. (1971). Self-disclosure: An experimental analysis of the transparent self. New York: Wiley.

Kim, J., McHale, S. M., Crouter, A. C., \& Osgood, D. W. (2007). Longitudinal linkages between sibling relationships and adjustment from middle childhood through adolescence. Developmental Psychology, 43(4), 960-973.

Lempers, J. D., \& Clark-Lempers, D. S. (1992). Young, middle, and late adolescents’ comparisons of the functional importance of five significant relationships. Journal of Youth and Adolescence, 21, 53-96.

Lockwood, R. L., Kitzmann, K., \& Cohen, R. (2001). The impact of sibling warmth and conflict on children’s social competence with peers. Child Study Journal, 31(1), 47-69.

Parker, J. G., \& Asher, S. R. (1993). Friendship and friendship quality in middle childhood: Links with peer group acceptance and feeling of loneliness and social dissatisfaction. Developmental Psychology, 29(4), 611-621.

Rose, A. J., \& Rudolph, K. D. (2006). A review of sex differences in peer relationship processes: Potential trade-offs for the emotional and behavioral development of girls and boys. Psychological Bulletin, 132(1), 98-131.

Rose, A. J., Schwartz-Mette, R. A., Smith, R. L., Asher, S. R, Swenson, L. P., Carlson, W., \& Waller, E. M. (2012). How girls and boys expect disclosure about problems will make them feel: Implications for friendships. Child Development, 83(3), 844-863.

Rubin, K. H., Bukowski, W. M., \& Parker, J. (2006). Peer interactions, relationships, and groups. In N. Eisenberg (Ed.), Handbook of child psychology: Social, emotional, and personality development (6th ed., pp. 571-645). New York: Wiley.

Smetana, J. G., \& Metzger, A. (2008). Don't ask, don't tell (your mother or father): Disclosure and nondisclosure in parent-adolescent relationships. In M. Kerr, H. Stattin, \& R. Engels (Eds.), What can parents do: New insights into the role of parents in adolescent problem behavior (pp. 65-87). New York: Wiley.

Smetana, J. G., Metzger, A., Gettman, D. C., \& Campione-Barr, N. (2006). Disclosure and secrecy in adolescent-parent relationships. Child Development, 77(1), 201-217.

Stattin, H., \& Kerr, M. (2000). Parental monitoring: A reinterpretation. Child Development, 71(4), 1072-1085. 
International Journal of Child, Youth and Family Studies (2013) 2: 274-300

Swenson, L. P., \& Rose, A. J. (2009). Friend's knowledge of youth internalizing and externalizing adjustment: Accuracy, bias, and the influence of gender, grade, positive friendship quality, and self-disclosure. Journal for Abnormal Child Psychology, 37(6), 887-901.

Updegraff, K., McHale, S. M., \& Crouter, A. C. (2002). Adolescents’ sibling relationship and friendship experiences: Developmental patterns and relationship linkages. Social Development, 11(2), 182-204.

Updegraff, K. A., \& Obeidallah, D. A. (1999). Young adolescents' patterns of involvement with siblings and friends. Social Development, 8, 53-69.

van Aken, M. A. G., \& Asendorpf, J. B. (1997). Support by parents, classmates, friends and siblings in preadolescence: Covariation and compensation across relationships. Journal of Social and Personal Relationships, 14, 79-93.

Yau, J. O., Tasopoulos-Chan, M., \& Smetana, J. G. (2009). Disclosure to parents about everyday activities among American adolescents from Mexican, Chinese, and European backgrounds. Child Development, 80(5), 1481-1498.

Yeh, H. C., \& Lempers, J. D. (2004). Perceived sibling relationships and adolescent development. Journal of Youth and Adolescence, 33(2), 133-147. 
International Journal of Child, Youth and Family Studies (2013) 2: 274-300

\section{Table 1. Definitions and Examples of Interview Coding Scheme}

Topics of Self-disclosure

(a) Family: Interactions with parents, siblings, and/or relatives (e.g., family events, pets)

(b) Peer: Interactions with best friend and other peers (e.g., future plans, hanging out)

(c) Academic: Related to school (e.g., grades received, interactions with teachers)

(d) Interest in the opposite sex: Romantic interest and/or interactions with a boyfriend or girlfriend (e.g., crushes)

(e) Shared interests: Related to hobbies (e.g., video games, music, reading)

Problems Disclosed

(a) Family: Conflict with parents, siblings, and/or relatives (e.g., divorce, arguing with brother or sister)

(b) Peer: Conflict with best friend and other peers (e.g., bullying, gossip)

(c) Academic: Related to school (e.g., failing, falling behind in school work) 
International Journal of Child, Youth and Family Studies (2013) 2: 274-300

Table 2. Descriptive Statistics for Self-disclosure Recipients and Frequency of Disclosure

\begin{tabular}{|c|c|c|c|c|c|c|c|c|c|}
\hline & \multicolumn{2}{|c|}{$\begin{array}{l}\text { Grade } 4 \\
(n=46)\end{array}$} & \multicolumn{4}{|c|}{$\begin{array}{l}\text { Grade } 6 \\
(n=47)\end{array}$} & \multicolumn{3}{|c|}{$\begin{array}{l}\text { Both Grades } \\
\qquad(N=93)\end{array}$} \\
\hline & $n$ & $\%$ & $\chi^{2}$ & $n$ & $\%$ & $\chi^{2}$ & $n$ & $\%$ & $\chi^{2}$ \\
\hline \multicolumn{10}{|l|}{ General Disclosure } \\
\hline To Sibling Only & 1 & 2 & \multirow{4}{*}{$45.65 * *$} & 2 & 4 & \multirow{4}{*}{$23.28 * *$} & 3 & 3 & \multirow{4}{*}{$91.20 * *$} \\
\hline To Friend Only & 12 & 26 & & 16 & 34 & & 28 & 30 & \\
\hline Both & 30 & 65 & & 29 & 62 & & 59 & 63 & \\
\hline Neither & 3 & 7 & & 0 & 0 & & 3 & 3 & \\
\hline \multicolumn{10}{|l|}{$\begin{array}{l}\text { Disclosure Freq. } \\
\text { to Sibling }\end{array}$} \\
\hline Not Often & 11 & 24 & & 7 & 15 & & 18 & 19 & \\
\hline Sometimes & 12 & 26 & & 6 & 13 & & 18 & 19 & \\
\hline Often & 2 & 4 & & 9 & 19 & & 11 & 12 & \\
\hline Very Often & 6 & 13 & & 9 & 19 & & 15 & 16 & \\
\hline \multicolumn{10}{|l|}{$\begin{array}{l}\text { Disclosure Freq. } \\
\text { to Friend }\end{array}$} \\
\hline Not Often & 12 & 26 & & 14 & 30 & & 26 & 28 & \\
\hline Sometimes & 17 & 37 & & 15 & 32 & & 32 & 34 & \\
\hline Often & 3 & 7 & & 7 & 15 & & 10 & 11 & \\
\hline Very Often & 10 & 22 & & 9 & 19 & & 19 & 20 & \\
\hline
\end{tabular}

$* p<.05 .{ }^{* *} p<.01$ 
International Journal of Child, Youth and Family Studies (2013) 2: 274-300 
International Journal of Child, Youth and Family Studies (2013) 2: 274-300

Table 3. Descriptive Statistics and McNemar's Test Results for Self-Disclosure Topics and Problems

\begin{tabular}{|c|c|c|c|c|c|c|c|c|c|c|c|c|c|c|c|}
\hline & \multicolumn{5}{|c|}{ Grade $4(n=46)$} & \multicolumn{5}{|c|}{ Grade $6(n=47)$} & \multicolumn{5}{|c|}{ Both Grades $(N=93)$} \\
\hline & \multicolumn{2}{|c|}{ To Sibling } & \multicolumn{2}{|c|}{$\begin{array}{c}\text { To Best } \\
\text { Friend } \\
\end{array}$} & \multirow{2}{*}{$\begin{array}{c}\text { McNemar's } \\
p\end{array}$} & \multicolumn{2}{|c|}{ To Sibling } & \multicolumn{2}{|c|}{$\begin{array}{l}\text { To Best } \\
\text { Friend }\end{array}$} & \multirow{2}{*}{$\begin{array}{c}\text { McNemar's } \\
p\end{array}$} & \multicolumn{2}{|c|}{ To Sibling } & \multicolumn{2}{|c|}{$\begin{array}{l}\text { To Best } \\
\text { Friend }\end{array}$} & \multirow{2}{*}{$\begin{array}{c}\text { McNemar's } \\
p\end{array}$} \\
\hline & $n$ & $\%$ & $n$ & $\%$ & & $n$ & $\%$ & $n$ & $\%$ & & $n$ & $\%$ & $n$ & $\%$ & \\
\hline \multicolumn{16}{|l|}{ Topics of Disclosure } \\
\hline Family & 3 & 7 & 6 & 13 & ns & 4 & 9 & 1 & 2 & $n s$ & 7 & 8 & 7 & 8 & ns \\
\hline Peer & 3 & 7 & 8 & 17 & $n s$ & 5 & 11 & 13 & 28 & $n s$ & 8 & 9 & 21 & 23 & .011 \\
\hline Academic & 12 & 26 & 12 & 26 & ns & 18 & 38 & 17 & 36 & ns & 30 & 32 & 29 & 31 & $n s$ \\
\hline $\begin{array}{l}\text { Interest in Opposite } \\
\text { Sex }\end{array}$ & 1 & 2 & 5 & 11 & $n s$ & 4 & 9 & 14 & 30 & .021 & 5 & 5 & 19 & 20 & .004 \\
\hline Shared Interests & 8 & 17 & 13 & 28 & $n s$ & 3 & 6 & 12 & 26 & .004 & 11 & 12 & 25 & 27 & .003 \\
\hline \multicolumn{16}{|l|}{ Problems Disclosed } \\
\hline Family & 12 & 26 & 19 & 41 & ns & 20 & 43 & 26 & 55 & ns & 32 & 34 & 45 & 48 & $n s$ \\
\hline Peer & 19 & 41 & 32 & 70 & .007 & 28 & 60 & 42 & 89 & .003 & 47 & 51 & 74 & 80 & .001 \\
\hline Academic & 21 & 46 & 33 & 72 & .004 & 27 & 57 & 41 & 87 & .004 & 48 & 52 & 74 & 80 & .001 \\
\hline
\end{tabular}


International Journal of Child, Youth and Family Studies (2013) 2: 274-300

Table 4. Summary of Chi-square Test Results for Self-disclosure Gender Differences

\begin{tabular}{|c|c|c|c|c|c|c|c|c|c|c|c|c|c|c|c|}
\hline & \multicolumn{5}{|c|}{$4^{\text {th }}$ Grade } & \multicolumn{4}{|c|}{$6^{\text {th }}$ Grade } & \multicolumn{6}{|c|}{ Both Grades } \\
\hline & \multicolumn{2}{|c|}{ Males } & \multicolumn{2}{|c|}{ Females } & \multirow[t]{2}{*}{$\chi^{2}$} & \multicolumn{2}{|c|}{ Males } & \multicolumn{2}{|c|}{ Females } & \multirow[t]{2}{*}{$\chi^{2}$} & \multicolumn{2}{|c|}{ Males } & \multicolumn{2}{|c|}{ Females } & \multirow[t]{2}{*}{$\chi^{2}$} \\
\hline & No & Yes & No & Yes & & No & Yes & No & Yes & & No & Yes & No & Yes & \\
\hline \multicolumn{16}{|l|}{ Topics of Disclosure } \\
\hline \multicolumn{16}{|l|}{ Shared Interests } \\
\hline To Best Friend & 11 & 10 & 18 & 3 & $5.46^{*}$ & 9 & 9 & 24 & 3 & $8.35^{* *}$ & 20 & 19 & 42 & 6 & $13.78 * *$ \\
\hline To Sibling & 10 & 6 & 13 & 2 & 2.36 & 11 & 3 & 17 & 0 & $4.03 *$ & 21 & 9 & 30 & 2 & $5.98^{*}$ \\
\hline \multicolumn{16}{|l|}{ Problems Disclosed } \\
\hline \multicolumn{16}{|l|}{ Family } \\
\hline To Best Friend & 14 & 10 & 13 & 9 & .003 & 12 & 7 & 9 & 19 & $4.41 *$ & 26 & 17 & 22 & 28 & 2.51 \\
\hline To Sibling & 21 & 3 & 13 & 9 & $4.80^{*}$ & 13 & 6 & 14 & 14 & 1.57 & 34 & 9 & 27 & 23 & $6.44^{*}$ \\
\hline \multicolumn{16}{|l|}{ Peer } \\
\hline To Best Friend & 11 & 13 & 3 & 1 & $5.62 *$ & 1 & 18 & 4 & 24 & .97 & 12 & 31 & 7 & 43 & 2.75 \\
\hline To Sibling & 17 & 7 & 10 & 12 & 3.05 & 9 & 10 & 10 & 18 & .64 & 26 & 17 & 20 & 30 & $3.87^{*}$ \\
\hline
\end{tabular}

$* p<.05 . * * p<.01$

Note. The relevant comparisons for males versus females are presented horizontally (e.g., 10 males versus 3 females disclosed to their best friend about shared interests). 
International Journal of Child, Youth and Family Studies (2013) 2: 274-300

Table 5. Summary of Chi-square Tests Results for Self-disclosure Relationship Dyad Differences

\begin{tabular}{|c|c|c|c|c|c|c|c|}
\hline & No & Yes & No & Yes & No & Yes & \\
\hline & \multicolumn{2}{|c|}{ Sisters } & \multicolumn{2}{|c|}{ Brothers } & \multicolumn{2}{|c|}{ Opposite-Sex } & $\chi^{2}$ \\
\hline General Disclosure & 8 & 22 & 7 & 25 & 8 & 22 & $7.15 *$ \\
\hline \multirow[t]{2}{*}{ Family Problems } & 15 & 15 & 27 & 5 & 19 & 12 & $8.49 *$ \\
\hline & \multicolumn{2}{|c|}{ Male Friends } & \multicolumn{2}{|c|}{ Brothers } & & & \\
\hline \multicolumn{8}{|l|}{ Topics of Disclosure } \\
\hline Academic & 26 & 13 & 15 & 10 & & & $6.66^{*}$ \\
\hline \multicolumn{8}{|l|}{ Problems Disclosed } \\
\hline \multirow[t]{2}{*}{ Academic } & 11 & 32 & 17 & 15 & & & $5.06 *$ \\
\hline & \multicolumn{2}{|c|}{ Sisters } & \multicolumn{2}{|c|}{ Female Friends } & & & \\
\hline \multicolumn{8}{|l|}{ Topics of Disclosure } \\
\hline Shared Interests & 20 & 2 & 42 & 6 & & & $9.40 * *$ \\
\hline
\end{tabular}


International Journal of Child, Youth and Family Studies (2013) 2: 274-300

Table 6. Descriptive Statistics for the Sibling Relationship and Friendship Activity Questionnaires

\begin{tabular}{|c|c|c|c|c|c|c|}
\hline & \multicolumn{2}{|c|}{$\begin{array}{l}\text { Grade } 4 \\
(n=46)\end{array}$} & \multicolumn{2}{|c|}{$\begin{array}{l}\text { Grade } 6 \\
(n=47)\end{array}$} & \multicolumn{2}{|c|}{$\begin{array}{l}\text { Both Grades } \\
\qquad(N=93)\end{array}$} \\
\hline & $M$ & $S D$ & $M$ & $S D$ & $M$ & $S D$ \\
\hline \multicolumn{7}{|c|}{$\begin{array}{l}\text { Sibling Relationship } \\
\text { Questionnaire }\end{array}$} \\
\hline Warmth & 3.21 & .80 & 3.37 & .71 & 3.29 & .76 \\
\hline Power & 3.05 & .65 & 3.31 & .62 & 3.18 & .64 \\
\hline Rivalry & 2.87 & .51 & 2.73 & .51 & 2.79 & .54 \\
\hline Conflict & 3.13 & .99 & 2.68 & 1.02 & 2.91 & 1.03 \\
\hline Total & 3.10 & .58 & 3.15 & .49 & 3.12 & .54 \\
\hline \multicolumn{7}{|l|}{$\begin{array}{l}\text { Friendship Activity } \\
\text { Questionnaire }\end{array}$} \\
\hline Companionship & 3.90 & .77 & 3.88 & .84 & 3.89 & .81 \\
\hline Help & 3.94 & .76 & 4.04 & .66 & 3.99 & .71 \\
\hline Closeness & 4.11 & .75 & 4.16 & .64 & 4.14 & .69 \\
\hline Security & 4.20 & .58 & 4.21 & .66 & 4.20 & .62 \\
\hline Conflict & 2.50 & .98 & 2.45 & .90 & 2.48 & .94 \\
\hline Total & 3.80 & .55 & 3.80 & .49 & 3.80 & .52 \\
\hline
\end{tabular}


International Journal of Child, Youth and Family Studies (2013) 2: 274-300

Table 7. Summary of ANOVA Results for Self-disclosure and Relationship Quality

\begin{tabular}{lccc}
\hline & $\begin{array}{c}\text { Discloses to Sibling } \\
(n=62)\end{array}$ & $\begin{array}{c}\text { Does Not Disclose to Sibling } \\
(n=31)\end{array}$ & $F(d f)$ \\
& $M(S D)$ & $M(S D)$ & \\
\hline Sibling Relationship & & & \\
Questionnaire & $3.47(0.71)$ & $2.93(S D=0.73)$ & $F(1,91)=11.95^{* *}$ \\
$\quad$ Warmth & $2.88(2.63)$ & $2.63(S D=0.57)$ & $F(1,91)=4.37^{*}$ \\
Rivalry & $3.07(0.96)$ & $2.58(S D=1.10)$ & $F(1,91)=4.84^{*}$ \\
\hline
\end{tabular}

${ }^{*} p<.05 * * p<.01$ 
International Journal of Child, Youth and Family Studies (2013) 2: 274-300

\section{Endnotes}

' In Quebec, all children attend elementary school (kindergarten to Grade 6) and then enter high school in Grade 7. Therefore, no participants had yet experienced a school transition.

"We did not directly measure social class, but our assessment is based on the catchment areas for the suburban and inner city (e.g., eligible for subsidized programs as determined by the government) schools where the data were collected. In Quebec, immigrant children are not eligible for the English school system and must attend the French system; thus all children in the study were English-speaking. For children to be eligible to attend the English school system, one parent must have been educated in English at the primary or secondary level in Canada, thus restricting the ethnic diversity of the sample to second generation (or more) English-speaking families, most of whom happen to be Caucasian in the Montreal area. 